\title{
RESEARCH
}

Open Access

\section{High frequency of methotrexate intolerance in longstanding rheumatoid arthritis: using the methotrexate intolerance severity score (MISS)}

\author{
Jéssica Martins Amaral ${ }^{1 *}$ (D) Maria José Menezes Brito ${ }^{2}$ and Adriana Maria Kakehasi ${ }^{3}$
}

\begin{abstract}
Background: Methotrexate (MTX) intolerance is frequent, and its early identification may impact treatment, leading to timely changes in medication that may promote patient compliance and better control of rheumatoid arthritis (RA). The objective of this study was to identify the frequency of, and risk factors for, MTX intolerance using the Brazilian Portuguese version of the Methotrexate Intolerance Severity Score (MISS) questionnaire in patients with RA.

Methods: This cross-sectional study was performed between April 2018 and April 2019 and enrolled patients with RA in regular use of oral or subcutaneous MTX for at least 3 months. Patients were invited to answer the Brazilian Portuguese version of the MISS questionnaire, and MTX intolerance was defined by a score $\geq 6$ points. Age, sex, disease duration, time of MTX use, dose, route of administration, concomitant medications, comorbidities, smoking, and Disease Activity Score for 28joint (DAS28) data were collected from institutional medical records.

Results: Among 120 patients, 103 (85.8\%) were female, the mean age was $61( \pm 12.5)$ years, the mean duration of disease was $16( \pm 10.3)$ years, and the average duration of MTX use was $7( \pm 5.5)$ years. The frequency of MTX intolerance was $21.6 \%$. The most frequent symptoms reported after the use of MTX were nausea (92.3\%), abdominal pain (46.1\%), and vomiting (30.7\%). Behavioral symptoms occurred in $96.1 \%$ of patients with MTX intolerance, the most frequent being restlessness and irritability. Patients who used corticosteroids were more likely to develop MTX intolerance than those not using corticosteroids (odds ratio $=2.73 ; 95 \%$ confidence interval, 1.06 to 7.06; $p=0.038$ ). Conversely, increasing age showed marginally significant association with decreased risk of MTX intolerance $(p=0.059)$.

Conclusions: The use of the MISS questionnaire disclosed high frequencies of anticipatory, associative, and behavioral symptoms in MTX-intolerant patients, and the use of corticosteroid increases the risk of MTX intolerance. We suggest that the MISS questionnaire be used routinely in clinical practice.
\end{abstract}

Keywords: Rheumatoid arthritis, Methotrexate, Questionnaire, Intolerance

\footnotetext{
* Correspondence: jessicamartinsmk@yahoo.com.br

${ }^{1}$ Post Graduate Program in Sciences Applied to Adult Health Care, Federal University of Minas Gerais, Avenida Alfredo Balena, 190 room 193 Santa Efigênia, Belo Horizonte, Minas Gerais ZIP 30130-100, Brazil Full list of author information is available at the end of the article
}

(c) The Author(s). 2020 Open Access This article is licensed under a Creative Commons Attribution 4.0 International License, which permits use, sharing, adaptation, distribution and reproduction in any medium or format, as long as you give appropriate credit to the original author(s) and the source, provide a link to the Creative Commons licence, and indicate if changes were made. The images or other third party material in this article are included in the article's Creative Commons licence, unless indicated otherwise in a credit line to the material. If material is not included in the article's Creative Commons licence and your intended use is not permitted by statutory regulation or exceeds the permitted use, you will need to obtain permission directly from the copyright holder. To view a copy of this licence, visit http://creativecommons.org/licenses/by/4.0/ 


\section{Background}

Rheumatoid arthritis (RA) is a systemic, autoimmune inflammatory disease whose manifestations occur in synovial joints and in different organs and systems, causing chronic pain, bone erosion and progressive disability [1]. Methotrexate (MTX) is the most important diseasemodifying antirheumatic drug in the treatment of RA. Use of MTX is indicated for first-line therapy of RA and occupies a prominent position in many guidelines and recommendations for the treatment of rheumatic diseases [1-3]. In spite of its effectiveness and low cost, MTX can cause gastrointestinal side effects, such as abdominal pain, nausea, vomiting and diarrhea $[4,5]$. Although folic acid supplementation during MTX treatment may reduce such effects, many patients discontinue treatment, something that negatively impacts disease control and quality of life [4]. In addition, patients may develop anticipatory symptoms, which occur prior to MTX intake, and associative symptoms, when patients think about the drug, as well as behavioral symptoms [6, 7]. These adverse effects arise as a response to previous symptoms experienced by patients on MTX and are not often clinically evident; therefore, they are often inadequately managed [7].

Given the lack of specific tools to assess the adverse effects associated with the use of MTX, the Methotrexate Intolerance Severity Score (MISS) was developed [7]. This is currently the only questionnaire that formally evaluates MTX intolerance taking into account the most frequent side effects as well as anticipatory, associative and behavioral symptoms - which are very important in the identification of intolerance. This tool was developed and validated in patients with juvenile idiopathic arthritis [7], and it has also been validated for use in patients with juvenile idiopathic arthritis in the French language [8]. Furthermore, the MISS questionnaire has also been used to determine the prevalence of MTX intolerance in patients with RA and psoriatic arthritis in several countries [4, 7-9]. More recently, the MISS questionnaire has also been validated in Brazilian Portuguese for use in adults with RA [10].

Early identification of MTX intolerance may impact treatment, so that changes in medications may occur at the right time, promoting patient compliance and, consequently, disease control [9].

Thus, the objective of this study was to identify the frequency of MTX intolerance using the Brazilian Portuguese version of the MISS questionnaire in patients with RA in a Brazilian rheumatology service, as well as factors that may be associated with MTX intolerance.

\section{Methods}

\section{Study design and approval}

This cross-sectional study was performed in a University rheumatology service in Brazil from April 2018 to April
2019. The study was approved by the institutional ethics committee, and all patients provided a signed informed consent form.

\section{Patient eligibility and assessment}

One hundred and 20 patients diagnosed with RA according to the American College of Rheumatology (ACR) 1987 criteria [11] or ACR/European League Against Rheumatism 2010 criteria [12], and in regular use of oral or subcutaneous MTX for at least 3 months, were invited to answer the MISS questionnaire; all patients had participated in the validation stage of the Brazilian Portuguese version of the MISS. Patients who had psychiatric illnesses or history of noncompliance with earlier treatments were excluded.

The MISS questionnaire contains twelve items divided into four dimensions: abdominal pain (three questions), nausea (three questions), vomiting (two questions), and behavioral complaints (four questions). The symptoms occurring after MTX intake, before MTX intake (anticipatory symptoms) and/or when thinking of taking MTX (associative symptoms). The possible answers (and corresponding score in points) for each item are no complaints (0), mild complaints (1), moderate complaints (2), and severe complaints (3). Points are summed to give a score that may range from 0 to 36 . The definition of MTX intolerance is given by a score of 6 or more points, with at least 1 point in the anticipatory, associative, or behavioral symptoms [7]. Additional data, collected from institutional medical records, were age, sex, disease duration, time of MTX use, dose, route of administration, concomitant medications, other comorbidities, smoking, and disease activity as assessed by Disease Activity Score in 28 joints (DAS28) [13].

The Brazilian Portuguese version of the MISS questionnaire is shown in the Additional file 1.

\section{Statistical analysis}

The primary outcome of interest was MTX intolerance. Univariate analyses were performed to explore the association of demographic and clinical variables with MTX intolerance; categorical variables were assessed using Pearson's Chi-Square test or Fisher's exact test, depending on the number of cases and categories. Quantitative variables were assessed using t-test or the MannWhitney test, depending on their distribution; normality was assessed using the Shapiro-Wilk test, and homoscedasticity using the Levene test. Variables in the univariate analyses with a $p$-value $<0.25$ were inserted in a multivariate logistic regression model to assess independent risk factors for MTX intolerance. Odds ratios (OR) from the multivariate model were computed in order to indicate an increased risk of MTX intolerance with values above 1.00. Model fit was assessed using the 
Hosmer-Lemeshow test, and statistical significance was considered for two-sided $p$-values $<0.05$.

\section{Results}

Demographic and clinical characteristics

Among the 120 patients who participated in the study, $103(85.8 \%)$ were female, the mean age was $61( \pm 12.5)$ years, the mean duration of disease was 16 ( \pm 10.3) years, and the average duration of MTX use was $7( \pm$ 5.5) years. These and other patient characteristics are shown in Table 1.

\section{Frequency and characteristics of MTX intolerance}

Considering all 120 patients, 27 (22.5\%) presented symptoms of anticipation, $36(30 \%)$ presented symptoms of association, and $41(34.2 \%)$ showed behavioral symptoms. Table 2 displays the prevalence of symptoms among patients with and without MTX intolerance. MTX intolerance was present in 26 of 120 patients (21.6\%), of whom women. The most frequent symptom after MTX intake among patients with MTX intolerance was nausea, in 24 (92.3\%) patients, followed by abdominal pain, in 12 (46.1\%) patients, and vomiting, in eight (30.7\%) patients. Among these same patients, the most frequent pre-treatment symptoms in the nausea domain were associative in $22(84.6 \%)$ and anticipatory in 18 (69.2\%) patients. Therefore, all 26 patients with MTX intolerance presented symptoms in the nausea domain either after taking MTX or as anticipatory or associative symptoms. In the abdominal pain domain, associative and anticipatory symptoms occurred in three (11.5\%) and two (7.6\%) patients with MTX intolerance, respectively. Anticipatory symptom related to vomiting occurred in two (7.6\%) of those patients. Finally, behavioral symptoms occurred in 25 (96.1\%) patients with MTX intolerance; among these symptoms, the most frequent were restlessness and irritability (Table 2).

\section{Predictors of MTX intolerance}

In univariate analyses, age as continuous variable $(p=$ $0.089)$, female sex $(p=0.022)$, MTX dose above $17.5 \mathrm{mg} /$ week $(p=0.126)$, and use of non-steroidal antiinflammatory agents $(p=0.203)$, proton-pump inhibitor $(p=0.164)$, corticosteroids $(p=0.054)$, and antiemetics $(p=0.217)$, were deemed possibly associated with the presence of MTX intolerance, due to a $p$-value $<0.25$, as pre-specified in Methods, and thus carried forward to the multivariate analysis. This study did not reveal association of MTX intolerance with other variables, such as subcutaneous or oral formulation, or folic acid dosing. Of these variables, only age and use of corticosteroids were retained in the final logistic regression model, presented in Table 3. In this multivariate analysis, use of corticosteroid was significantly associated with MTX
Table 1 Baseline characteristics of the patients at the time of completing the MISS questionnaire

\begin{tabular}{|c|c|}
\hline Characteristics & $\boldsymbol{N}=120$ \\
\hline \multicolumn{2}{|l|}{ Qualitative } \\
\hline Female (\%) & $103(85.8)$ \\
\hline MTX, subcutaneous (\%) & $66(55)$ \\
\hline \multicolumn{2}{|l|}{ MTX dose (mg/week) } \\
\hline$<10(\%)$ & $1(0.8)$ \\
\hline $10.1-17.5(\%)$ & $31(25.8)$ \\
\hline$>17.5(\%)$ & $88(73.4)$ \\
\hline Leflunomide (\%) & $29(24.2)$ \\
\hline Nonsteroidal anti-inflammatory drugs (\%) & $9(7.5)$ \\
\hline Disease-modifying antirheumatic drugs - biological (\%) & $28(23.3)$ \\
\hline Corticosteroids (\%) & $63(52.5)$ \\
\hline Proton-pump inhibitors (\%) & $56(46.7)$ \\
\hline Antiemetics (\%) & $1(0.8)$ \\
\hline \multicolumn{2}{|l|}{ Folic acid } \\
\hline No (\%) & $7(5.8)$ \\
\hline 5 mg/week (\%) & $92(76.7)$ \\
\hline 10 mg/week or more (\%) & $21(17.5)$ \\
\hline DAS 28 moderate and high disease activity (\%) & $51(45.5)$ \\
\hline \multicolumn{2}{|l|}{ Smoking } \\
\hline No (\%) & $74(62.2)$ \\
\hline Current smoker (\%) & $15(12.6)$ \\
\hline Ex-smoker (\%) & $30(25.2)$ \\
\hline Seropositive RA (\%) & $92(76.7)$ \\
\hline Hypertension (\%) & $68(56.7)$ \\
\hline Diabetes mellitus (\%) & $29(24.2)$ \\
\hline Dyslipidemia (\%) & $36(30.0)$ \\
\hline Hypothyroidism (\%) & $15(12.5)$ \\
\hline Fibromyalgia (\%) & $10(8.3)$ \\
\hline Gastroesophageal reflux disease (\%) & $12(10.3)$ \\
\hline Antidepressant (\%) & $24(20)$ \\
\hline \multicolumn{2}{|l|}{ Quantitative } \\
\hline Mean age, years (SD) & $61(12.5)$ \\
\hline Mean disease duration, years (SD) & $16(10.3)$ \\
\hline Mean MTX usage duration, years (SD) & $7(5.5)$ \\
\hline Mean dose of MTX, mg/week (SD) & $20(5.1)$ \\
\hline Mean DAS28 (SD) & $3.25(3.1)$ \\
\hline
\end{tabular}

DAS 28 Disease activity score in 28 joints; MTX Methotrexate; SD Standard deviation

intolerance $(\mathrm{OR}=2.73 ; 95 \%$ confidence interval $[\mathrm{CI}]$, 1.06 to $7.06 ; p=0.038$ ). With regard to age, the association was not statistically significant, but the results indicate a trend for a 3\% reduction in the risk of MTX intolerance for every increase of 1 year of age $(O R=0.97$; $95 \% \mathrm{CI}, 0.93$ to $1.0 ; p=0.059$ ). 
Table 2 Prevalence of MTX-related symptoms in MTX-tolerant and MTX-intolerant patients

\begin{tabular}{lll}
\hline Symptoms & \multicolumn{1}{c}{ MTX-intolerant } & $\begin{array}{l}\text { MTX-tolerant } \\
\mathbf{N}=26(\%)\end{array}$ \\
\hline Abdominal pain & & \\
After taking MTX & $12(46.15)$ & $3(3.19)$ \\
Anticipatory & $2(7.69)$ & $2(2.12)$ \\
Associative & $3(11.53)$ & $1(1.06)$ \\
Nausea & & \\
After taking MTX & $24(92.30)$ & $44(46.80)$ \\
Anticipatory & $18(69.23)$ & $7(7.44)$ \\
Associative & $22(84.61)$ & $13(13.82)$ \\
Vomiting & & $9(9.57)$ \\
After taking MTX & $8(30.76)$ & $1(1.06)$ \\
Anticipatory & $2(7.69)$ & $10(10.63)$ \\
Behavioral complaints & & $1(1.06)$ \\
Restlessness & $20(76.92)$ & $7(7.44)$ \\
Crying & $11(42.30)$ & $4(4.25)$ \\
Irritability & $20(76.92)$ & \\
Refusal of MTX & $16(61.53)$ &
\end{tabular}

MTX Methotrexate

\section{Discussion}

In the current study, we have found a frequency of $21.6 \%$ of MTX intolerance among RA patients. The most frequent symptoms reported after the use of MTX were nausea (92.3\%), abdominal pain (46.1\%), and vomiting (30.7\%). Patients who used corticosteroids were nearly three times more likely to develop MTX intolerance than those not using corticosteroids. Conversely, increasing age was associated with a decreasing risk of MTX intolerance.

To our knowledge, this is the first study developed in Brazil using a validated questionnaire to assess MTX intolerance in patients with RA. The prevalence of MTX intolerance we found is within the range reported in studies using the MISS questionnaire reported elsewhere. For example, a study performed in Utrecht, in the Netherlands, found a prevalence of MTX intolerance of $11 \%$ among patients with RA and psoriatic arthritis [14]. In a study conducted in Pakistan, this frequency was 33.3\% among RA patients [4]. Finally, a recent study from Saudi Arabia among RA patients who used MTX for at least 3 months found that $39.5 \%$ of them had a positive score for MTX intolerance using the MISS questionnaire [15]. The frequency of the most common symptoms reported by our patients after the use of MTX were similar to those from the Dutch study, in which $100 \%$ of the patients reported nausea, $46.9 \%$ abdominal pain, and $31.3 \%$ vomiting [14].

In addition to experiencing gastrointestinal symptoms after receiving the drug, patients in our study with MTX intolerance exhibited anticipatory, associative, and behavioral symptoms. The occurrence of these symptoms before the ingestion of MTX supports the idea that classical conditioning mechanisms play an important role in the development of MTX intolerance [7]. The presence of these symptoms has also been noted in studies among patients with juvenile idiopathic arthritis [7, 16]. The study that developed and applied the MISS questionnaire in children with juvenile idiopathic arthritis highlighted the most frequently conditioned stimuli reported at the outpatient clinic: the yellowish color of the medication and the fluids used to administer MTX, such as water or orange juice. Such stimuli may lead to the conditioned response of anticipatory and associative effects [7]. It is accepted that such symptoms occur due to stimulation of higher centers of the central nervous system [17]. In line with this hypothesis, cognitivebehavioral therapy may have benefits in the treatment of MTX-intolerant patients [7, 18]. A recent study in patients with juvenile idiopathic arthritis showed positive results using desensitization and pre-processing of ocular movements to treat MTX-intolerant patients, promoting more adherence to treatment and increasing patient's quality of life [18]. Other measures that can be taken to ameliorate symptoms include decreasing the dose of MTX [19], changing the route of administration from oral to parenteral, introduction of folic acid $[5,20]$, and introducing an antiemetic [21].

It is worth noting that often times the anticipatory, associative and behavioral symptoms are not clinically evident, hence not adequately monitored. This can affect the continuity of the treatment and lead to a decrease in the

Table 3 Multivariate analysis of risk factors for methotrexate intolerance

\begin{tabular}{|c|c|c|c|c|c|c|}
\hline \multirow[t]{2}{*}{ Variable } & \multirow[t]{2}{*}{ Coefficient } & \multirow{2}{*}{$\begin{array}{l}\text { Standard } \\
\text { error }\end{array}$} & \multirow{2}{*}{$\begin{array}{l}\boldsymbol{P} \text { - } \\
\text { value }\end{array}$} & \multirow[t]{2}{*}{ OR } & \multicolumn{2}{|c|}{ 95\% confidence interval } \\
\hline & & & & & Lower limit & Upper limit \\
\hline \multicolumn{7}{|l|}{ Corticosteroids } \\
\hline Yes & 1.00 & 0.48 & 0.038 & 2.73 & 1.06 & 7.06 \\
\hline \multicolumn{7}{|l|}{ No } \\
\hline Age (years) & -0.03 & 0.02 & 0.059 & 0.97 & 0.93 & 1.00 \\
\hline
\end{tabular}


patient's quality of life [7]. In view of this, it is very important to monitor MTX intolerance in daily clinical practice, which makes the use of the MISS questionnaire advantageous, as it allows for early detection of symptoms. In our findings, no association of MTX intolerance with other variables was observed. Ensuring adequate tolerance and greater adherence to MTX can prevent therapeutic failures, minimize the high cost of treating rheumatic diseases, and ultimately promote better disease control.

Several studies have indicated that corticosteroid use increases the risk of gastrointestinal adverse events [22, 23]. Our findings suggest that patients who used corticosteroids were more likely to develop MTX intolerance. Glucocorticoids may have dual action on the gastric mucosa: physiological gastroprotective and pathological proulcerogenic one. The prolongation of the action, instead of the dose of exogenous glucocorticoids, can be a significant factor for the undesirable effects of glucocorticoids on the gastric mucosa [24]. Since previous studies using the MISS questionnaire have found no association between concomitant medications and MTX intolerance, further studies are needed to elucidate the association between corticosteroid use and MTX intolerance. Our study suggests a trend for decreasing risk of MTX intolerance with increasing age. Previous studies among patients with RA and psoriatic arthritis have also shown an association between age and MTX intolerance, with older patients ( $>65$ years) being less likely to have MTX intolerance than their younger counterparts [14]. With regard to other potential risk factors for MTX intolerance, further, large-sample studies are needed to better elucidate additional issues associated with MTX intolerance, given its large impact on non-compliance with drug treatment.

\section{Conclusion}

In conclusion, MTX intolerance is relatively frequent in RA patients, even those under treatment for prolonged periods of time. The use of the MISS questionnaire discloses high frequencies of anticipatory, associative, and behavioral symptoms in MTX-intolerant patients, and such symptoms potentially contribute to lower adherence to treatment. The use of corticosteroid seemingly increases the risk of MTX intolerance. The early identification of MTX intolerance may allow more adequate medical treatment, with timely changes in medication that may improve patient compliance, disease control, and well-being. Therefore, we strongly recommend that the evaluation of MTX intolerance be included in daily clinical practice, and for that purpose we suggest using the MISS questionnaire.

\section{Study limitations}

The relatively small number of participants is a limitation of this study. The data were collected from a single tertiary hospital, which might limit the generalization of our findings to the general population. Furthermore, other studies are needed to elucidate the association between age and corticosteroid use and MTX intolerance.

\section{Supplementary information}

Supplementary information accompanies this paper at https://doi.org/10. 1186/s42358-020-00145-5.

Additional file 1. Brazilian Portuguese version of the MISS questionnaire

\section{Abbreviations}

ACR: American college of rheumatology; Cl: Confidence interval; MISS: Methotrexate intolerance severity score; MTX: Methotrexate; OR: Odds ratio; RA: Rheumatoid arthritis

\section{Acknowledgements}

Authors acknowledges editorial assistance funded by AbbVie.

\section{Authors' contributions}

JMA collected, analyzed and interpreted the patient data regarding the identification of MTX intolerance, and was a major contributor in writing the manuscript. MJMB was an important contributor in writing the manuscript. AMK analyzed and interpreted the patient data and was a major contributor in writing the manuscript. The author (s) read and approved the final manuscript.

\section{Funding}

This study was funded by the Coordination for the Improvement of Higher Education Personnel (CAPES, Brazil). Editorial assistance was provided by Everardo Delforge Saad (DENDRIX, Sao Paulo, Brazil) and funded by AbbVie.

\section{Availability of data and materials}

The datasets used and/or analyzed during the current study are available from the corresponding author on reasonable request.

\section{Ethics approval and consent to participate}

This study was approved by the Research Ethics Committee of the Federal University of Minas Gerais - CAAE 68327217.4.0000.5149. Patients signed the informed consent form approved by the institution's research ethics committee.

Consent for publication

Not applicable.

\section{Competing interests}

The authors declare that they have no competing interests.

\section{Author details}

${ }^{1}$ Post Graduate Program in Sciences Applied to Adult Health Care, Federal University of Minas Gerais, Avenida Alfredo Balena, 190 room 193 Santa Efigênia, Belo Horizonte, Minas Gerais ZIP 30130-100, Brazil. 'Applied Nursing Department, Nursing School Federal University of Minas Gerais, Belo Horizonte, Minas Gerais, Brazil. ${ }^{3}$ Post Graduate Program in Sciences Applied to Adult Health Care, Federal University of Minas Gerais, Belo Horizonte, Minas Gerais State, Brazil.

Received: 16 April 2020 Accepted: 11 August 2020

Published online: 26 August 2020

\section{References}

1. Smolen JS, Aletaha D, McInnes IB. Rheumatoid arthritis. Lancet. 2016; 388(10055):2023-38.

2. Mota L, Kakehasi AM, Gomides APM, Duarte A, Cruz BA, Brenol CV, et al. 2017 recommendations of the Brazilian Society of Rheumatology for the pharmacological treatment of rheumatoid arthritis. Adv Rheumatol. 2018;58(1):2.

3. Singh JA, Saag KG, Bridges SL Jr, Akl EA, Bannuru RR, Sullivan MC, et al. 2015 American College of Rheumatology Guideline for the treatment of rheumatoid arthritis. Arthritis Rheumatol. 2016;68(1):1-26. 
4. Fatimah N, Salim B, Nasim A, Hussain K, Gul H, Niazi S. Frequency of methotrexate intolerance in rheumatoid arthritis patients using methotrexate intolerance severity score (MISS questionnaire). Clin Rheumatol. 2016;35(5):1341-5.

5. Brunner HI, Johnson AL, Barron AC, Passo MH, Griffin TA, Graham TB, et al. Gastrointestinal symptoms and their association with health-related quality of life of children with juvenile rheumatoid arthritis: validation of a gastrointestinal symptom questionnaire. J Clin Rheumatol. 2005;11(4):194-204.

6. van der Meer A, Wulffraat NM, Prakken BJ, Gijsbers B, Rademaker CM, Sinnema G. Psychological side effects of MTX treatment in juvenile idiopathic arthritis: a pilot study. Clin Exp Rheumatol. 2007;25(3):480-5.

7. Bulatovic M, Heijstek MW, Verkaaik M, van Dijkhuizen EH, Armbrust W, Hoppenreijs EP, et al. High prevalence of methotrexate intolerance in juvenile idiopathic arthritis: development and validation of a methotrexate intolerance severity score. Arthritis Rheum. 2011;63(7):2007-13.

8. Chausset A, Fargeix T, Pereira B, Echaubard S, Duquesne A, Desjonqueres M, et al. MISS questionnaire in French version: a good tool for children and parents to assess methotrexate intolerance. Clin Rheumatol. 2017;36(6):1281-8.

9. Virdi P, Singh B, Singh R. Role of methotrexate intolerance severity score (miss) in rheumatoid arthritis to know methotrexate intolerance: a 2-year prospective study. Int J Adv Res. 2017;5:2542-8.

10. Amaral JM, Brito MJM, Kakehasi AM. Cultural adaptation and validation of the methotrexate intolerance severity score in Brazilian Portuguese for adults with rheumatoid arthritis. J Clin Rheumatol. 2019.

11. Arnett FC, Edworthy SM, Bloch DA, McShane DJ, Fries JF, Cooper NS, et al. The American rheumatism association 1987 revised criteria for the classification of rheumatoid arthritis. Arthritis Rheum. 1988;31(3):315-24.

12. Aletaha D, Neogi T, Silman AJ, Funovits J, Felson DT, Bingham CO 3rd, et al. 2010 rheumatoid arthritis classification criteria: an American College of Rheumatology/European league against rheumatism collaborative initiative. Arthritis Rheum. 2010;62(9):2569-81.

13. Prevoo MLL, van't Hof MA, Kuper HH, et al. Modified disease activity scores that include twenty-eight joint counts. Arthritis Rheum. 1995;38:44-48.14.

14. Calasan MB, van den Bosch OF, Creemers MC, Custers M, Heurkens AH, van Woerkom JM, et al. Prevalence of methotrexate intolerance in rheumatoid arthritis and psoriatic arthritis. Arthritis Res Ther. 2013;15(6):R217.

15. Albaqami J, Alshalhoub R, Almalag H, Dessougi M, Al Harthi A, Bedaiwi MK, et al. Prevalence of methotrexate intolerance among patients with rheumatoid arthritis using the Arabic version of the methotrexate intolerance severity score. Int J Rheum Dis. 2019;22(8):1572-7.

16. van Dijkhuizen EH, Pouw JN, Scheuern A, Hugle B, Hardt S, Ganser G, et al. Methotrexate intolerance in oral and subcutaneous administration in patients with juvenile idiopathic arthritis: a cross-sectional, observational study. Clin Exp Rheumatol. 2016;34(1):148-54.

17. Hornby PJ. Central neurocircuitry associated with emesis. Am J Med. 2001; 111 (Suppl 8A):106S-12S.

18. Hofel L, Eppler B, Storf M, Schnobel-Muller E, Haas JP, Hugle B. Successful treatment of methotrexate intolerance in juvenile idiopathic arthritis using eye movement desensitization and reprocessing - treatment protocol and preliminary results. Pediatr Rheumatol Online J. 2018;16(1):11.

19. Murray KJ, Lovell DJ. Advanced therapy for juvenile arthritis. Best Pract Res Clin Rheumatol. 2002;16(3):361-78.

20. Alsufyani K, Ortiz-Alvarez O, Cabral DA, Tucker LB, Petty RE, Malleson PN. The role of subcutaneous administration of methotrexate in children with juvenile idiopathic arthritis who have failed oral methotrexate. J Rheumatol. 2004;31 (1): 179-82.

21. Ravelli A, Martini A. Methotrexate in juvenile idiopathic arthritis: answers and questions. J Rheumatol. 2000;27(8):1830-3.

22. Moghadam-Kia S, Werth VP. Prevention and treatment of systemic glucocorticoid side effects. Int J Dermatol. 2010;49(3):239-48.

23. Piper JM, Ray WA, Daugherty JR, Griffin MR. Corticosteroid use and peptic ulcer disease: role of nonsteroidal anti-inflammatory drugs. Ann Intern Med. 1991;114(9):735-40.

24. Filaretova L, Podvigina T, Yarushkina N. Physiological and pharmacological effects of glucocorticoids on the gastrointestinal tract. Curr Pharm Des. 2020;26(25):2962-70

\section{Publisher's Note}

Springer Nature remains neutral with regard to jurisdictional claims in published maps and institutional affiliations.

\section{Ready to submit your research? Choose BMC and benefit from}

- fast, convenient online submission

- thorough peer review by experienced researchers in your field

- rapid publication on acceptance

- support for research data, including large and complex data types

- gold Open Access which fosters wider collaboration and increased citations

- maximum visibility for your research: over $100 \mathrm{M}$ website views per year

At $\mathrm{BMC}$, research is always in progress.

Learn more biomedcentral.com/submissions 